\title{
Erythrocyte Protoporphyrin Levels in Patients with Friedreich's and other Ataxias
}

\author{
R. O. MORGAN, G. NAGLIE, D.F.HORROBIN AND A.BARBEAU
}

SUMMARY: Of 13 patients with Friedreich's ataxia (Type Ia) and 17 with type Ila recessive ataxias, all were found to have levels of "free erythrocyte protoporphyrin" (FEP) above the normal range. The rise in $F E P$ in Friedreich's ataxia correlated well with the age of the individual and thus appears to be related to the course of the disease. Subjects with olivo-ponto-cerebellar atrophy. Charlevoix syndrome, Duchenne muscular dystrophy, and Parkinson's disease were also found to

RÉSUMÉ: Nous avons trouvé des niveaux élevés de protoporphyrines érythrocytaires libre (FEP) chez chacun de 13 patients avec ataxie de Friedreich (type Ia) et 17 avec une ataxie récessive (type IIa). L'augmentation des FEP dans l'ataxie de Friedreich, et ses variantes, est reliée à l'âge des individus et donc semble liée à l'évolution de la maladie. Une légère augmentation des FEP fut également observée dans l'OPCA, le syndrome de Charlevoix, la dystrophie have significantly elevated FEP, although the distribution overlapped with the normal range.

The finding of elevated FEP may' indicate a relative heme deficienc' $y$ in ataxia due to inhibition of ferrochelatase leading to a state of ineffective, persistent erythropoiesis. The possibility' of a prostaglandin abnormality being related to this defect and to the pathogenesis of ataxia is considered.

musculaire de Duchenne et la maladie de Parkinson, même s'il y' a chevauchement des données avec les valeurs normales.

Cette augmentation des FEP indique peut-être une déficience en hème dans l'ataxie par inhibition de la ferrochelatase avec, comme conséquence, une érythroporèse inefficace et persistante. Nous discutons du rôle possible des prostaglandines dans cette anomalie.
From the Clinical Research Institute of Montreal.

Reprint requests for the complete supplement on Friedreich's Ataxia (Phase Two, Part Two) to:

Dr. André Barbeau, Clinical Research Institute of Montreal, 110 Pine Avenue West, Montreal, Quebec, Canada, H2W IR7.

\section{INTRODUCTION}

Despite the many" neurological disturbances of inherited disorders of heme metabolism, the "porphyrias" (Goldberg, 1959), there have been, conversely, very few investigations of hematological indices in the hereditary ataxias (Szanto and Gallyas, 1966; Barbeau et al, 1976). A possible role of prostaglandins (PG's) and thromboxanes in ataxia has been suggested (Horrobin, 1978) and is supported by the importance of essential fatty acid metabolism in the CNS myelination process (Merton and Meade, 1977; Trapp and Bernsohn, 1978). Essential fatty acids are precursors of prostaglandins. Heme plays an important role in $\mathrm{PG}$ endoperoxide synthesis (Hemler et al, 1976) and, conversely, PG's are important modulators of erythropoiesis and attending heme synthesis (Dukes et al, 1975). If there is abnormal PG metabolism in hereditary ataxias, either the cause or consequence of the disease, then there should be abnormalities of porphyrin-heme biosynthesis as well. In particular, our recent studies have demonstrated a critical role for PG's in regulating protoporphyrin accummulation in chick embryo liver cells in culture (unpublished observations). The ease and simplicity of erythrocyte porphyrin analysis encouraged us to attempt to verify the predicted porphyrin abnormality in blood samples from ataxic individuals.

\section{SUBJECTS AND METHODS}

Heparinized blood samples were obtained from 164 patients of both sexes at this and other clinics in the province of Quebec. The ataxia groups included were type Ia (autosomal 
recessive) Friedreich's ataxia $(n=13)$, type Ila recessive ataxias endemic to New Brunswick $(n=4) *$ and the Rimouski region of Quebec $(n=13)$, autosomal dominant olivo-pontocerebellar atrophy $(n=10)$, and Charlevoix syndrome $(n=32), \quad a$ recessive spastic ataxia. Known obligatory heterozygotes or children at risk for these conditions were also included $(n=47)$. For comparison, several other groups were studied, including Duchenne muscular dystrophy $(n=11)$, Werdnig-Hoffman syndrome $(n=3)$, myasthenia gravis $(n=1)$, Wilson's disease $(n=1)$, Huntington's chorea $(n=1)$, and Parkinson's disease $(n=22)$. Normal control blood samples were obtained from healthy laboratory personnel, 5 male and 1 female in their twenties. Hematocrit or microhematocrit values were obtained for all individuals.

Assays for FEP were performed in quadruplicate on $50 \mu \mathrm{l}$ aliquots of frozen-thawed whole blood lysates or, in the case of patients with muscular dyśtrophy, on fresh whole blood following an overnight fast. The method used was the double-extraction method described by Sassa et al (1975) modified only for larger volumes. $3 \mathrm{ml}$ ethylacetate: glacial acetic acid (2:1, v:v) were mixed with $50 \mu \mathrm{l}$ blood in a large test tube. $3 \mathrm{ml} 0.5 \mathrm{~N}$ $\mathrm{HCl}$ were then mixed in and the two phases allowed 15-30 min to separate. The lower aqueous phase (now $4 \mathrm{ml}$ ) containing better than $80 \%$ of all porphyrins was transferred by Pasteur pipet to a separate test tube. Fluorescence emission spectra were obtained using a Hitachi PerkinElmer model 204 spectrofluorometer equipped with an R777 Hammamatsu red-sensitive photomultiplier. The excitation wave length was $410 \mathrm{~nm}$ and emission peak heights at 602 and 660 $\mathrm{nm}$ were determined for each sample after zeroing with solvent and calibrating with standard solutions of $50 \mathrm{pM}$ Rhodamine B in ethylene glycol and $10 \mathrm{nM}$ protoporphyrin $1 \mathrm{X}$ in $0.5 \mathrm{~N}$ HCl:glacial acetic acid (3:1, v:v) the peak height ratio $(602 / 660 \mathrm{~nm})$ allowed identification of protoporphyrin as the main porphyrin component in the samples analysed, and the second peak height at $660 \mathrm{~nm}$ was used for calculation of concentra-

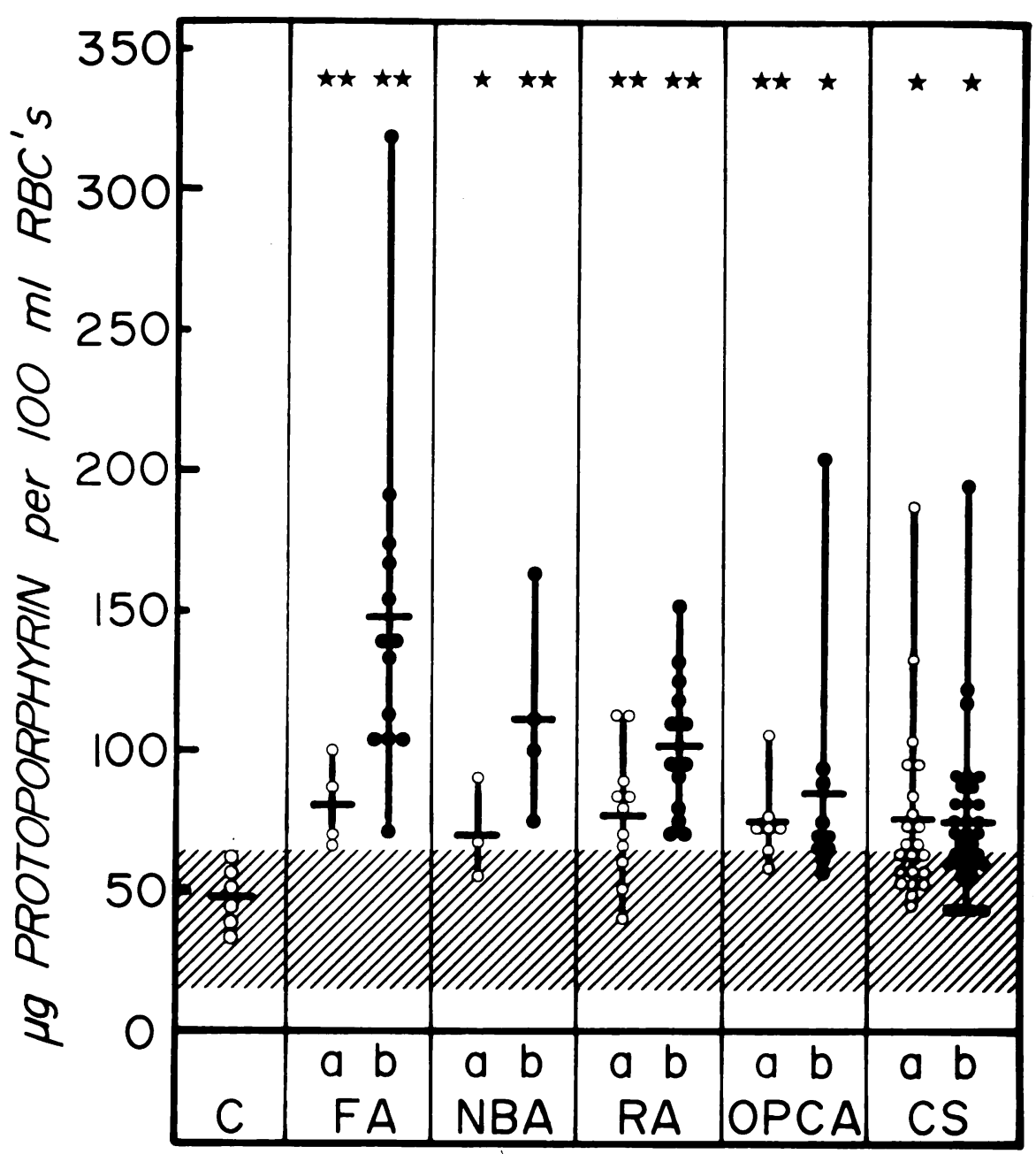

Figure I-Free erythrocyte protoporphyrin levels in ataxic patients and their relatives. Abbreviations identify the groups as normal controls (C), Friedreich's ataxia (FA), "New Brunswick Ataxia" (NBA), "Rimouski Ataxia" (RA), Olivo-ponto-cerebellar atrophy (OPCA) and Charlevoix Syndrome (CS). Solid circle symbols denote affected individuals (b-columns) while open circles (a-columns) represent obligatory heterozygotes or, in the OPCA group, children at risk. The shaded area covers the expected range of normal values. Vertical lines span the range of experimental values obtained while horizontal lines mark the mean value. Stars appearing above a subgroup indicate a statistically significant difference from the normal control group: 1 star, $p<0.05$ or 2 stars, $\mathrm{p}<0.005$.

tions. Assays of uroporphyrinogen-1synthetase were performed as described by Sassa et al (1974) on $10 \mu \mathrm{l}$ aliquots of frozen-thawed whole blood lysates. Statistical comparisons of experimental data were made using the Student's two-tailed t-test.

\footnotetext{
" "New Brunswick" and "Rimouski" recessive altaxias are slowly progressive forms of attaxia, most likels variants of Friedreich's ataxia. They will be described elsewhere.
}

\section{RESULTS}

The mean FEP for our normal controls was $48 \pm 11 \quad$ (S.D.) $\mu \mathrm{g}$ protoporphyrin $/ 100 \mathrm{ml}$ red blood cells with a range of 34 to 62 . These values are similar to ones previously reported: $56 \pm 10 \quad$ (mean \pm S.D.) $\mu \mathrm{g}$ protoporphyrin/100 ml RBC's (Anderson et al, 1977), range 35 to 65 $\mu \mathrm{g} / 100 \mathrm{ml}$ R BC's (Orfanos et al, 1977) and range 20 to $50 \mu \mathrm{g} 100 \mathrm{ml} \mathrm{RBC's}$ 


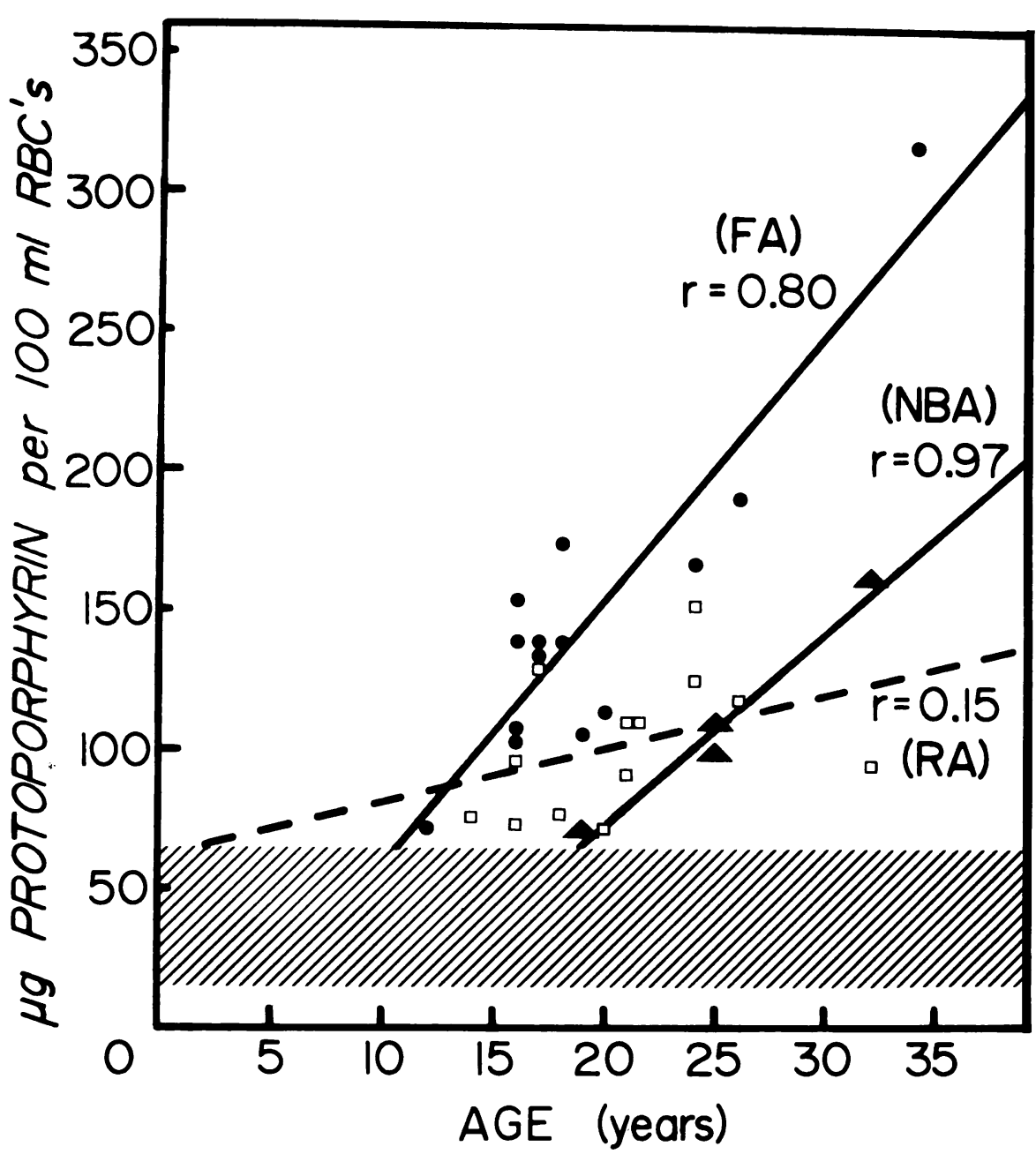

Figure 2-Free erythrocyte protoporphyrin in ataxias as a function of age. Lines represent patients with Friedreich's ataxia (FA, $n=13$, solid circles), "New Brunswick Ataxia" (NBA, $n=4$, solid triangle symbols) and "Rimouski Ataxia" (RA, $n=13$, open squares). Correlation coefficients are given as r-values adjacent to the corresponding line.

(Granick et al, 1972). Values may be slightly higher in young children and females (Orfanos et al, 1977; Krammer et al, 1954). No consistent or marked sex differences were noted in this study. With regard to the above data, the shaded area in Figs. 1, 2 and 3 is intended to represent a normal range of FEP from 15 to $65 \mu \mathrm{g}$ protoporphyrin/100 ml RBC's.

It is apparent from the distributions of FEP in Fig. 1 that individuals with types Ia and IIa ataxia showed highly significant elevations of FEP; indeed, there was no overlap of FEP values between those 30 patients and the normal range. Groups of OPCA and CS and obligatory heterozygotes for types Ia and IIa hereditary ataxias showed lesser but nonetheless significant elevations of FEP with some overlap in the normal range. Subjects with Rimouski ataxia had FEP levels significantly greater than their corresponding obligatory heterozygotes which were in turn, significantly elevated over control levels. Differences between other ataxic individuals (FA and NBA) and their respective heterozygotes fell just short of significance, due to the small sample size of heterozygotes.

Among the ataxic patients there was excellent correlation of FEP levels with age or duration of the disease in the case of FA and the more slowly progressive NBA (Fig. 2). Within these two groups, FEP appeared to rise progressively above the normal range at about the same rate, but beginning at age 10 in FA and at age 20 in NBA.

In order to assess the "disease specificity" of the elevated FEP in ataxias, it was deemed of interest to investigate subjects with non-ataxic disorders. The results in Fig. 3 indicate that patients with progressive myopathies (DMD, WHS, MG) show relatively minor elevations of FEP and most have levels in the normal range. Those afflicted with Parkinson's disease, aged 23 to 78 years, displayed FEP values ranging from 54 to 127 $\mu \mathrm{g} / 100 \mathrm{ml}$ RBC's i.e. from the normal range to maximum levels that were significantly elevated but less than the maxima in ataxia groups.

Assays of uroporphyrinogen-lsynthetase, the third enzyme of the heme biosynthetic pathway, revealed a small but significant elevation of enzyme activity of 25 to $75 \%$ in ataxic patients and their relatives compared with control levels. Unfortunately, blood samples were subjected to one or more days at room temperature prior to assay due to a refrigerator breakdown. These data are therefore not shown as they likely underestimate the true elevation of uroporphyrinogen synthetase in ataxia.

\section{DISCUSSION}

This is the first report of a "paraporphyria" existing in ataxic disorders. Although there has been, hitherto, no recognized nosological association between ataxia and porphyria, the two diseases can nevertheless coexist in a single patient (Goldberg, 1959) and certain subgroups of both of these heterogenous diseases are well known to show a high incidence of diabetes mellitus, enhanced skin photosensitivity, and abnormal pituitary hormone regulation. It is of interest that acute intermittent porphyria was once considered to have a primary neurological basis characterized by defective acetylcholine synthesis, peripheral demyelination, and paralysis, thus illustrating the importance of heme metabolism in nerve function.

The elevations of FEP were most apparent in the patients with 
Friedreich's, New Brunswick, and Rimouski ataxias in which all observed values were above the normal range. Also, only in these three groups was there a clear difference between affected individuals and obligatory heterozygotes. In all three groups the mean value for the heterozygotes was above normal. In the Friedreich's and New Brunswick groups there was a highly significant correlation between age (and therefore severity of the disease) and the FEP values. The correlation was much weaker and not significant for the Rimouski group. This association between FEP and disease progress suggests that both the clinical features of the disease and the FEP abnormalities may be secondary to some underlying primary problem. The elevated FEP is not a cause of the disease but may provide clues as to the cause. It might also provide a readily available and sensitive monitor of new approaches to therapy.

FEP is known to be elevated in a variety of conditions including infection (Krammer et al, 1954), hemorrhage, iron deficiency, nutritional deficiency anaemias of vitamin E (Chou et al, 1978), or vitamin $B_{12}$ and copper (Allen, 1956), following birth, and after irradiation. Elevation of FEP is an indicator of stimulated erythropoiesis and an increased population of mitrochondria-containing erythroblasts and reticulocytes (Johnson and Schwartz, 1972) which are the only red blood cells engaged in active heme synthesis.

Elevations of FEP can result from a number of different abnormalities all pointing to a primary defect at the level of ferrochelatase, the final, regulatory mitochondrial enzyme of the heme pathway that inserts ferrous iron into the protoporphyrin ring (Fig. 4). Possible causes could be 1) a deficiency of the iron substrate 2) a decreased heme requirement or catabolism 3) inhibition of ferrochelatase, as through depletion of cofactors (see below) and / or 4) enhanced flux of intermediates through the porphyrin pathway following induction (derepression) of the rate-limiting enzyme ALA synthetase.

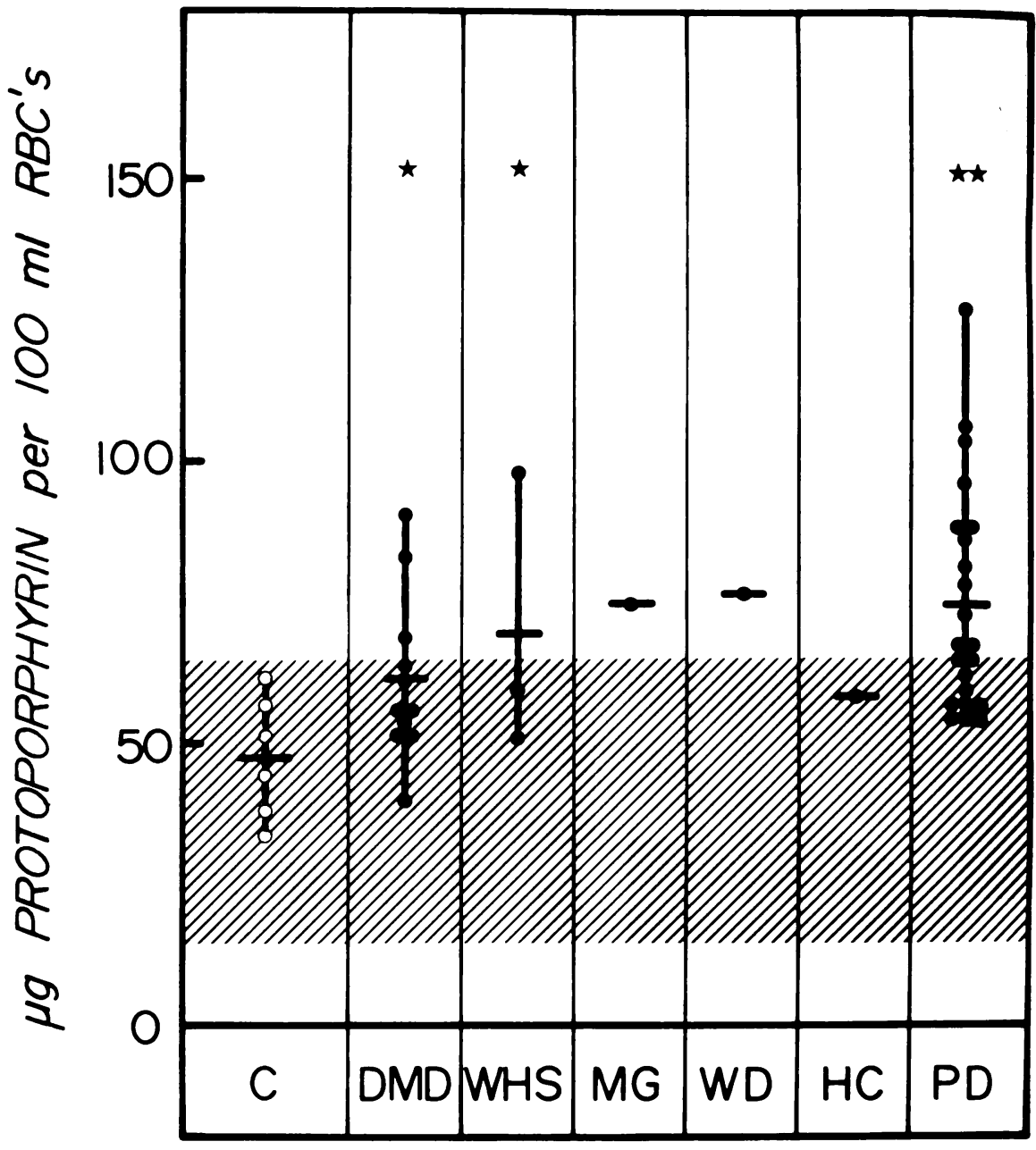

Figure 3-Free erythrocyte protoporphyrin levels in patients with non-ataxic disorders. Abbreviations identify the groups as normal controls (C), Duchenne Muscular Dystrophy (DMD), Werdnig-Hoffman Syndrome (WHS), Myasthenia Gravis (MG), Wilson's Disease (WD), Huntington's Chorea (HC) and Parkinson's Disease (PD). Explanations of data presentation, stars, and shading a re given in Figure 1. Note scale change from Figures 1 and 2.

Since plasma and tissue iron is normal or elevated in Friedreich's ataxia (Szanto and Gallyas, 1966) the first possibility seems unlikely. The recent findings of hyperbilirubinemia in a large percentage of ataxic individuals (Barbeau et al, 1976; Hamel et al, 1978) and the heme deficiency in brain mitochondrial cytochrome oxidase of lambs with enzootic ataxia allow us to eliminate the second possibility described above. Incidently, studies of experimental protoporphyria caused by pharmacologic inhibition of ferrochelatase have shown that accumulated protopor- phyrin can serve as an alternate source of bilirubin (Liem et al, 1977). Thus the third possibility, "inhibition of ferrochelatase" with consequent protoporphyria, could account for the observed hyperbilirubinemia which the aforementioned studies could not attribute to hemolytic anemia. Although erythrocyte turnover rate may be enhanced in Friedreich's ataxia (Szanto and Gallyas, 1966), hemolytic anemia could also be discounted on the basis of protoporphyrin, as opposed to coproporphyrin, accumulation in RBC's, the latter 


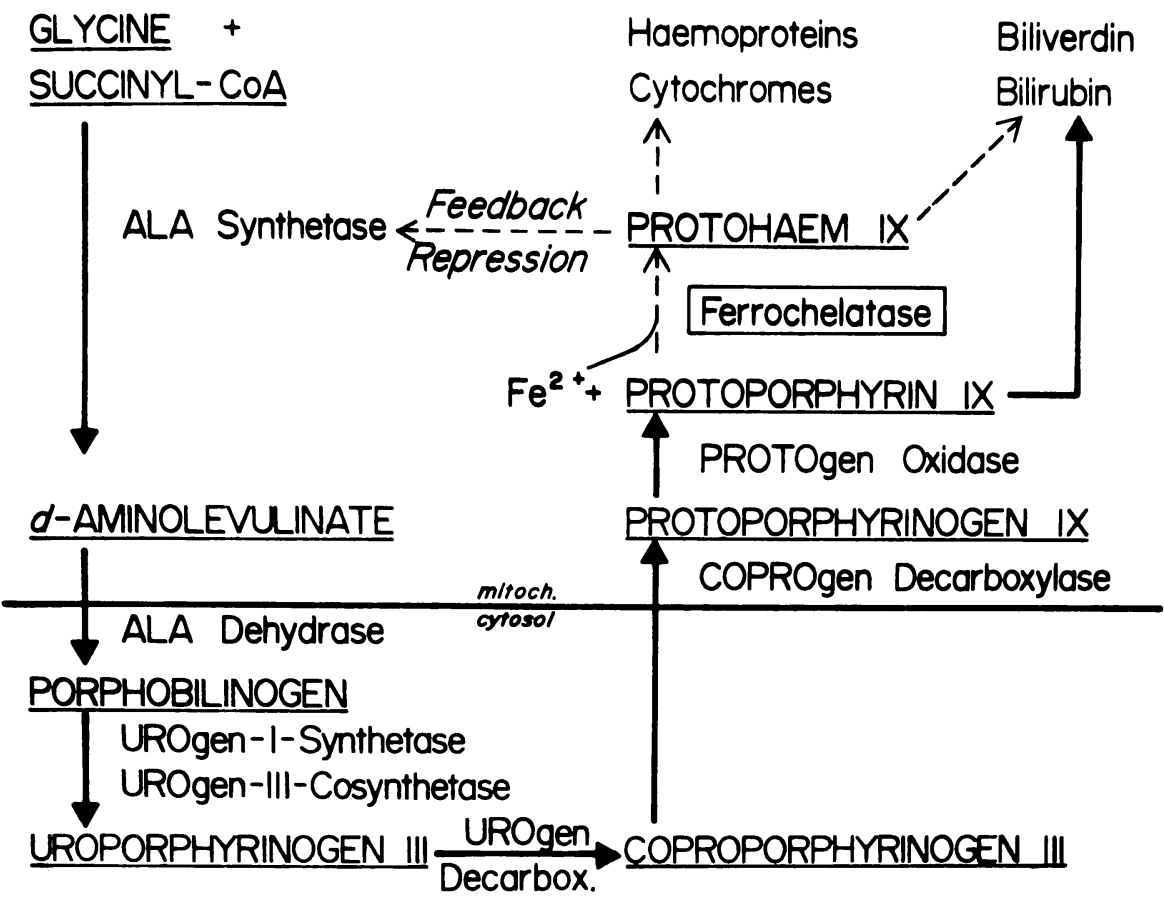

Figure 4-Synopsis of heme metabolism in ataxia. See text for discussion.

being primarily elevated in hemolytic anemias (Krammer et al, 1954).

The consequences of decreased conversion of protoporphyrin to heme would become manifest as a deficiency of heme proteins and enzymes in cells where heme serves an essential function. Diminished cytochrome activity and respiratory efficiency (Smith et al, 1976) and possible impaired conversion of tryptophan to nicotinic acid via tryptophan pyrrolase in animal ataxias may be examples of this (Fischl and Rabiah, 1964). Diminished cyclooxygenase activity with impairment of prostaglandin synthesis might also be anticipated (Hemler et al, 1976). Derepression of ALA synthetase is an essential prelude to porphyria and would be expected to be elevated in erythropoietic tissues.

To establish the cause of ferrochelatase inhibition we have considered possible depletion of essential enzyme cofactors $\mathrm{Cu}^{++}$(Wagner et al, 1976) and pyridoxal phosphate (Labbe and Nielsen, 1976). In addition, the importance of polyunsaturated fatty acids and calcium as they affect the mitochondrial environment are recognized determinants of ferrochelatase activity (Simpson and Poulson, 1977). Copper deficiency, known to be associated with the enzootic ataxia of lambs (Smith et al, 1976) and with elevated FEP in sheep (Allen, 1956), may or may not be a contributing factor in human ataxias. (Note the elevation of FEP in the one case of Wilson's disease, Fig. 3). Pyridoxal phosphate deficiency does not seem likely and is actually known to impair protoporphyrin biosynthesis since this vitamin is an essential cofactor for ALA synthetase which is rate-limiting for porphyrin biosynthesis.

We next considered a pharmacologic approach to understanding the relation between ataxia and apparent ferrochelatase inhibition. Curiously, substituted pyridine derivatives are used to produce experimental models of cerebellar ataxia viz. 3-acetylpyridine (Perry et al, 1976) and of protoporphyria due to ferrochelatase inhibition viz. 3,5-diethoxycarbonyl1,4-dihydrocollidine (De Matteis et al, 1973). On the other hand, certain pyridine derivatives such as nicotinic acid and nicotinamide are able to attentuate experimental porphyria
(Pinelli and Favalli, 1972; Gibbard and Schoental, 1977). Alteration of pyridine metabolism in hereditary ataxias has not been investigated.

The importance of unsaturated fatty acids and calcium in stimulating ferrochelatase activity prompted us to investigate the actions of prostaglandins on ferrochelatase activity. Preliminary studies in liver cell cultures have established that F-type prostaglandins are powerful modulators of ferrochelatase activity and protoporphyrin accumulation. Using this model system to study heme biosynthesis we have found that certain imidazole and pyridine derivatives known to inhibit thromboxane synthesis and enhance formation of F-type prostaglandins (Moncada et al, 1977; Wennmalm, 1977; Vincent and Zijlstra, 1978; Shimamoto et al, 1976) also produce marked effects on protoporphyrin accumulation. The action of vitamin $\mathbf{A}$ acid was also of interest in relation to three, perhaps coincidental observations: apart from its known ability to stimulate lipid peroxidation (prostaglandin synthesis), vitamin.A (as betacarotene) is unique in its ability to abolish symptoms of erythropoietic protoporphyria (Mathews-Roth et al, 1974) and finally, vitamin A deficiency has been used as a model of experimental ataxia (Howell and Thompson, 1967).

In conclusion, it appears that ataxia and elevated FEP may be related in conditions associated with deficiencies of copper, vitamin A, and/or essential fatty acids. Whether any of these nutritional deficiencies contribute to symptoms of hereditary ataxias is at present uncertain. Regretably, such nutritional models have a history of falling short when it comes to applying them to hereditary human diseases e.g. vitamin E's ineffectiveness in hereditary human muscular dystrophies. Elevated FEP may account in part for the hyperbilirubinemia previously observed in hereditary ataxias. Insofar as the mechanisms regulating porphyrin-heme biosynthesis are known or can be investigated pharmacologically, an understanding of the cause(s) of elevated FEP in ataxias may contribute ideas about the etiology of, 
and potential therapy for, human hereditary ataxias.

\section{ACKNOWLEDGEMENTS}

We thank the Canadian Muscular Dystrophy Association and L'Association Canadienne de l'Ataxie de Friedreich for financial support, and Ms. Danielle Bédard for her technical expertise and for her care of the patients.

\section{REFERENCES}

ALLEN, S. H. (1956) Effects of vitamin $B_{12}$ deficiency and of copper deficiency on the concentration of free protoporphyrin in the erythrocytes of sheep. Biochem. J. 63: 461469.

ANDERSON, K. E., S. SASSA, C. M. PETERSON and A. KAPPAS (1977). Increased erythrocyte uroporphyrinogen-1synthetase, delta-aminolevulinic acid dehydratase and protoporphyrin in hemolytic anemieas. Amer. J. Med. 63: 359-364.

BARBEAU, A., G. BRETON, B. LEMIEUX, R. F. BUTTER WORTH (1976). Bilirubin metabolism - preliminary investigation. Can. J. Neurol. Sci. 3: 365-372.

CHOU, A. C., G. O. BROUN AND C. D. FITCH (1978). Abnormalities of iron metabolism and erythropoiesis in vitamin Edeficient rabbits. Blood 52: 187-195.

DEMATTEIS, F., G. ABBRITTI and A. H. GIBBS (1973). Decreased liver porphyrinmetal chelatase in hepatic porphyria caused by 3,5-diethoxycarbonyl-1,4-dihydrocollidine. Biochem. J. 134: 717-727.

DUKES, P. P., N. A. SHORE, G. D. HAMMOND and J. A. ORTEGA (1975). Prostaglandins and erythropoietin action. In Nakao, K. et al (eds), Univ. Park Press, Baltimore, 1975, pp 3-14.

FISCHL, J. and S. RABIAH (1964). Determination of free and total indole-3-acetic acid and of the indole index. Clin. Chem. 10: 281-290.

GIBBARD, S. and R. SCHOENTAL (1977) Effect of nicotinamide on development and localization of tumors, and on excretion of porphyrins in urine of rats given hepatocarcinogen, diethylnitrosamine. Brit. J. Cancer 35: 254.

GOLDBERG, A. (1959). Acute intermittent porphyria. A study of 50 cases. Quart. J. Med. 28: 183-209.

GRANICK, S., S. SASSA, J. L. GRANICK, R. D. LEVERE and A. KAPPAS (1972). Assays for porphyrins, delta-aminolevulinic acid dehydratase, and uroporphyrinogen synthetase in micoliter samples of whole blood: Applications to metabolic defects involving the heme pathway. Proc. Nat. Acad. Sci. (U.S.A.) 69: 2381-2385.
HAMEL, E., D. BEDARD, F. LAVIOLETTE, R. F. BUTTERWORTH and A. BARBEAU (1978). Familial hyperbilirubinemia in Friedreich's ataxia. Can. J. Neurol. Sci. 5: 101-104.

HEMLER, M., W. E. M. LANDS and W. L. SMITH (1976). Purification of the cyclooxygenase that forms prostaglandins. Demonstration of two forms of iron in the holoenzyme. J. Biol. Chem. 251: 5575-5579.

HORROBIN, D. F. (1978) Prostaglandins: Physiology, Pharmacology and Clinical Significance. Eden Press, Montreal, 1978, pp. 259.

HOWELL, J. McC. and J. N. THOMPSON. (1967). Lesions associated with the development of ataxia in vitamin A-deficient chicks. Brit. J. Nutr. 21: 741-750.

JOHNSON, L. W. and S. SCHWARTZ. (1972). Relation of porphyrin content to red cell age: analysis by fractional hemolysis. Proc. Soc. Exp. Biol. Med. 139: 191-197.

KRAMMER, A., G. E. CARTWRIGHT and M. M. WINTROBE. (1954). The anemia of infection. XIX. Studies on free erythrocyte coproporphyrin and protoporphyrin. Blood 9: $183-188$

LABBE, R. F. and L. NIELSEN. (1976). Clinical-biochemical interpretations of erythrocyte protoporphyrin. Ferrochelatasepyridoxal phosphate studies. In Porphyrins in Human Diseases, First Int'l Porphyrin Meeting, Freiburg, 1975, Karger, Basel, 1976, pp. 141-147.

LIEM, H. H., K. MIYAI and U. MULLEREBERHARD. (1977). Effect of porphyrinogenic agents on protein synthesis and bilirubin formation by the isolated perfused rat liver. Biochim. Biophys. Acta 496: 52-64.

MATHEWS-ROTH, M., M. PATHAK, T. FITZPATRICK, L. HARBER and E. KASSE. (1974). Beta-carotene as an oral photoprotective agent in erythropoietic protoporphyria. J. Amer. Med. Ass. -28: 1004-1008.

MERTIN, J. and C. J. MEADE (1977). Relevance of fatty acids in multiple sclerosis. $\mathrm{Br}$. Med. Bull. 33: 67-71.

MONCADA, S., S. BUNTING, K. MULLANE, P. THOROGOOD, J. R. VANE, A. RAZ and P. NEEDLEMAN. (1977). Imidazole-selective inhibitor of thromboxane synthetase. Prostaglandins 13: 611-618.

ORFANOS, A. P., W. H. MURPHY and R. GUTHMA (1977). A simple fluorometric assay of protoporphyrin in erythrocytes as a screening test for lead poisoning. J. Lab. Clin. Med. 89: 659-665

PERRY, T. L., J. MACLEAN, T. L. PERRY and S. HANSEN (1976). Effect of 3acetylpyridine on putative neurotransmitter amino acids in rat cerebellum. Brain Res. 109: 632-635.
PINELli, A. and L. FAVALLI (1972). Antilipaemic and antiporphyric activity of nicotinic acid in allylisopropylacetamidetreated rats. Biochim. Biophys. Acta 279: 316-319.

SASSA, S., S. GRANICK, D. R. BICKERS, H. L. BRADLOW and A. KAPPAS (1974). A microassay for uroporphyrinogen 1 synthase, one of three abnormal enzyme activities in acute intermittant porphyria. and its application to the study of the genetics of this disease. Proc. Nat. Acad. Sci. (U.S.A.) 71: 732-736.

SASSA, S., S. GRANICK and A. KAPPAS (1975). Effect of lead and genetic factors on heme biosynthesis in the human red cell. Ann. N. Y. Acad. Sci. 244: 419-440.

SHIMAMOTO, T., Y. TAKASHIMA, M. KOBAYASHI, $K$. MORIYA and $T$. TAKAHASHI (1976). A specific thromboxane $\mathrm{A}_{2}$-antagonistic effect of pyridinolcarbamate and phthalazinol. Proc. Jap. Acad. 52: 591-594.

SIMPSON, D. M. and R. POULSON (1977). Effects of lipids on the activity of ferrochelatase. Biochim. Biophys. Acta 482: 461-469.

SMITH, R. M., W. S. OSBORNE-WHITE and B. L. O’DELL (1976). Cytochromes in brain mitochondria from lambs with enzootic ataxia. J. Neurochem. 26: 1145-1148.

SZANTO, J. and F. GALLYAS (1966). A study of iron metabolism in neuro-psychiatric patients. Hallervorden-Spatz disease. Arch. Neurol. 14: 438-442.

TRAPP, B. D. and J. BERNSOHN (1978). Essential fatty acid deficiency and CNS myelin - Biochemical and morphological observations. J. Neurol. Sci. 37: 249-266.

VINCENT, J. E. and F. J. ZIJLSTRA (1978). Nicotinic acid inhibits thromboxane synthesis in rat platelets. 7th Int'l Congress of Pharmacology. Paris, 1978, Abstract \#2012, pp 628.

WAGNER, G. S., M. L. DINAMARCA and T. R. TEPHLY (1976). Studies on ferrochelatase activity: Role in regulation of hepatic heme biosynthesis. In Porphyrins in Human Diseases. First Int'l Porphyrin Meeting, Freiburg, 1975, Karger, Basel, 1976, pp 1II-122.

WENNMALM, A. (1977). Nicotine stimulates prostaglandin formation in the rabbit heart. Br. J. Pharmacol. 59: 95-100. 